\title{
Theory of Social Proof and Legal Compliance: A Socio-Cognitive Explanation for Regulatory (Non) Compliance
}

\author{
Shubhangi Roy*(i) \\ Faculty of Law, University of Münster, Münster, Germany \\ Corresponding author: Shubhangi Roy, Email: rshubhangi93@gmail.com
}

(Received 28 September 2020; revised 05 October 2020; accepted 11 October 2020)

\begin{abstract}
Challenging the assumption of perfect legal knowledge, this Article employs social psychology to better understand how individuals make decisions about legal compliance under imperfect information conditions. It adapts the informational aspects of "social influence conception of criminal deterrence" to regulatory compliance at large. However, it conceptualizes social influence as more than just "visible deterrence." Social Psychology helps us to understand who, how many, and what kind of behaviors constitute adequate social proof to guide an individual's decision on compliance. Additionally, the interaction of social proof and legal compliance is considered within a dynamic framework in relation to specific rules and across the system. Within this framework, compliance/non-compliance cascades across different rules and can create a perception about legal compliance at large, which in turn guides initial expectations with respect to new laws. Over time, this can create high/low compliance equilibriums within which societies operate. Understanding this informational role that social influence plays in legal compliance can further our understanding of what motivates compliance, the potency of the expressive functions of law in societies operating within different compliance equilibriums, and inform policy discussions on how to improve compliance-both voluntary and through sanction/incentives.
\end{abstract}

Keywords: Social Proof; legal compliance; Compliance Cascades; Social Influence

"When people are free to do as they please, they usually imitate each other."

Eric Hoffer

\section{A. Introduction}

Most of us have experienced arriving at a new airport - in a new country, perhaps - and following the crowd to reach the appropriate carousal for our luggage, queuing behind people without knowing exactly why, to get a taxi, or exiting an airport and looking around to see if there are

\footnotetext{
* Shubhangi Roy is a doctoral student and research associate at the University of Münster. She holds a Master of Laws from the University of Chicago Law School, and a Bachelor of Arts and Bachelor of Laws from the Gujarat National Law University. Roy is also on the Faculty of Law at Jindal Global Law School, but currently on sabbatical. The article is part of the research project "Correcting Inequality through Law" that has received funding from the European Research Council (ERC) under the European Union's Horizon 2020 research and innovation programme (grant agreement No 817652). She would like to acknowledge the helpful feedback and guidance of Prof. Dr. Niels Petersen.
} 
others smoking before lighting a cigarette. More often than not, our faith in the wisdom of crowds is restored. Sometimes, we are proven wrong. That we will continue to look around in times of doubt is unchanged. The degree and extent of dependence on the behavior of others may vary. None of these illustrations were necessarily carrying any extrinsic motivations of the reputational kinds to comply with the popular norm. If confronted by someone for an explanation, perhaps our only explanation would be: "Because everyone else was doing so."1

This cognitive tendency to follow others when faced with any uncertainty is referred to in social psychology as the principle of social proof. It refers to the human tendency of viewing behavior as more appropriate when many others behave similarly. ${ }^{2}$ In the psychology literature, although social proof is a type of social influence, it is distinct from normative social influence-where the individual's motive for conformity is social prestige or to avoid social sanction. Alternatively, social proof is purely informational social influence. ${ }^{3}$ It is likely to lead to imitation and uniformity in behavior. It does not depend on any kind of third-party enforcement-unlike social norms or normative influence or the law — and is, therefore, more pervasive in its influence.

The issue of social influences that impact legal compliance has been considered previously. The legal literature on social norms and their impact on law discusses the inter-relation between normative social influences and the law. ${ }^{4}$ However, the informational social influence independent of its normative value has not been considered as substantially. It is a consequence of how the legal literature conceptualizes social influences. Social influences and why they impact individual decisions in favor or against compliance within the legal literature has been explored through the prism of "motivations," or incentives, the motivation of earning "self-esteem" or reputation ${ }^{5}$ external motivations or through an entrenchment of the norms-internal motivations. ${ }^{6}$ This Article argues that there exists a third value-a neutral reason for imitating others - which is not driven by any external — reputation- or sanction-based-or internal—morality- or entrenchment-based-motivation argument, but by the cognitive tendency of our brain to use behaviors of others as a proxy for any missing information when required to make a decision.

Earlier attempts at incorporating informational social influence within compliance literature focused on the information that improved legal enforcement communicates to the perception of law in society. Therefore, the focus was on the influence of visibly improved legal compliance on the general social perception of compliance. Kahan termed it as a social influence conception of deterrence. He noted that decisions of individuals to commit crimes are influenced by their perception of others' beliefs and intentions along with the traditional costs of crime, ${ }^{7}$ and that "the law can shape these perceptions." "It can be done through improved visible deterrence of misdemeanors and small crimes. The focus, therefore, is on law endogenously evolving social perception of law.

The order maintenance theory of policing also relies on this signaling function of preventing smaller misdemeanors on general rates of criminal activities in the area. ${ }^{9}$ This approach to deterrence recognizes that there could be subjectivity in an individual's perception and that the behavior of those around could inform this perception. But the central focus remains on legal

\footnotetext{
${ }^{1}$ Robert H. Gass \& John S. Seiter, Persuasion: Social Influence and Compliance 135-36 (2014).

${ }^{2}$ Robert B. Cialdini, Influence: The Psychology of Persuasion 87-126 (2007).

${ }^{3}$ Robert B. Cialdini \& Noah J. Goldstein, Social Influence: Compliance and Conformity, 55 ANN. Rev. PsYCH. 591, 622 (2005).

${ }^{4}$ See generally Eric A. Posner, Social Norms, Nonlegal SAnctions, AND the LAW (2007) (expounding on the interaction of law, on the one hand, and social norms and non-legal sanctions, on the other hand).

${ }^{5}$ Richard H. McAdams, The Origin, Development and Regulation of Norms, 96 Mich. L. Rev. 338, 433 (1997).

${ }^{6}$ Robert Cooter, Normative Failure Theory of Law, 82 CORNELL L. REV. 947, 979 (1997).

${ }^{7}$ Dan Kahan, Social Influence, Social Meaning and Deterrence, 83 VA. L. REV. 349, 395 (1997).

${ }^{8} I d$. at 350 .

${ }^{9}$ George L. Kelling \& Catherine M. Coles, Fixing Broken Windows: Restoring Order and Reducing Crime in OUR COMMUNities 151-56 (1996).
} 
enforcement evolving general perception into legal compliance. Therefore, it is a stronger recognition of the social influence of legal compliance rather than an exploration into the impact of social influence on legal compliance. To this extent, it operates within the same sphere as the literature on the instrumental functions of law. The ability of law to communicate a social preference to individuals, a focal point to coordinate behavior around, envisions a function of law that informs social perception. ${ }^{10}$ The flow of information, or signaling, continues to flow from law to society. Neither law nor society develop a framework that informs an understanding of what social proof is, when and how it manifests, or how it operates within a society vis-a-vis legal compliance.

The present Article aims to fill this gap in literature by focusing on understanding, in greater detail, the cognitive process by which informational social influence impacts our understanding of the law and legal compliance. In a dynamic context, how do these individual decisions create a general perception about legal compliance? Also discussed is how these perceptions are sustained through, and sustain informational social influence in favor of, or against, legal compliance. If the social meaning of law is derived from the text read in context, ${ }^{11}$ the focus of this Article is on a cognitive understanding of the context that those around us provide to our perception about legal compliance-in other words text.

Irrespective of the conception of legal compliance applied, the behaviors of other individuals, or social proof, have an impact both on our perceived legal consequences, or punishments, under the traditional deterrence model, as well as social costs, or reputational harm, under the social influence conception of deterrence. Social proof explanation to legal compliance is, therefore, not an alternative explanation of compliance. It aims to bring legal research closer to how individuals interact with laws in everyday life. What is relevant will continue to be guided by existing literature on deterrence, regulatory compliance, and so forth. The present framework merely adds another step to consider before we can presume that "law can change perception."

The first question to address is the extent of legal certainty under which individuals operate. Under perfect information conditions, we can all be what Veblen describes as "lightening calculators of pains and pleasures." 12 Information proxies are only relevant in the absence of accurate information. Therefore, in the next section, this Article describes briefly what multiple studies on legal awareness inform us about the state of legal uncertainty that individuals make their decisions in $(\mathrm{B}(\mathrm{I}))$. Not surprisingly, the level of uncertainty is high. But law is not the only subject matter in which we operate with incomplete information. In Section B(II)., this Article discusses an important socio-cognitive mechanism our brain utilizes to compensate for the missing knowledge. It utilizes the observable behavior of those around us as an informational proxy for the missing information. This cognitive explanation for our tendencies to imitate behavior or learn through a social learning process is referred to as the theory of social proof in psychology. This Article aims to identify and adapt the existing models of decision making under imperfect knowledge conditions to legal compliance across multiple disciplines. It focuses on the cognitive process through which the behavior of others influences our own decision to comply with the law.

In Section C, this Article discusses the components of social proof that are relevant for legal compliance. To conclude that the theory of social proof manifests in the society as merely a belief in the opinion of the majority would be a severe socio-cognitive oversimplification. Not all opinions are created equal. Some opinions matter more than others. Therefore, the "most people do so" explanation for or against legal compliance implicitly includes a caveat_- "most people around me do so." How our reference networks impact our behaviors and what constitutes a reference network for the purposes of social proof of law are discussed in Section C(I). In Section C(II), this Article uses availability and representative heuristics to further explain how the explanation "most

\footnotetext{
${ }^{10}$ See generally Richard H. McAdams, The Expressive Powers of LAw: Theories And Limits (2015) (explaining how the law creates compliance through its expressive power to coordinate behaviors and inform beliefs).

${ }^{11}$ See generally Lawrence Lessig, The Regulation of Social Meaning, 62 U. CHI. L. REV. 943 (1995).

${ }^{12}$ Kevin C. Kennedy, A Critical Appraisal of Criminal Deterrence Theory, 88 DicK. L. Rev. 1, 7 (1983).
} 
people around me are doing so" when investigated could have been cognitively extrapolated from as little as "he or she said we could do so." The sample space of behaviors required to constitute sufficient social proof to persuade our minds is not as high.

In Section D, this Article explores social proof within a time dynamic equilibrium. No laws are created in isolation, nor is compliance achieved overnight. Stories we hear about experiences with the legal system - the procedural legal system - and in reference to other laws also contribute to our social proof in favor of, or against, compliance. In this Section, the Article explores the cascading effects of initial behaviors on legal compliance both within a single rule and across multiple rules. A small number of early observable decisions about a new rule can create widespread compliance or non-compliance, meaning cascade within a single rule (when a few initial decisions of compliance/non-compliance with a legal rule starts a trend towards widespread compliance/noncompliance). This Article also discusses how our cognitive reliance on social proof to guide our decisions can create serious path dependencies both in favor of and against compliance, meaning cascades across different rules (when the general expectation of compliance/non-compliance within a legal system creates trends of compliance/non-compliance to a new law). Over time, this path dependency can contribute towards a general perception in favor of, or against, compliance even with respect to new rules within a legal system.

The concluding section discusses how the understanding of social proof developed within this Article augments literature on legal compliance. Recognizing the full framework within which our brain processes social proof highlights how the legally compartmentalized conception of social proof within the legal literature is problematic. Focusing on improving deterrence through increased visible order without keeping in mind procedural fairness could backfire as our minds, unlike the legal system, do not compartmentalize as neatly between procedural and substantive law. Similarly, identifying the general perception of society about legal compliance can help predict the potency of the expressive functions of law. Introducing a law with initially limited traditional enforcement in a society where the general perception is against compliance would yield little result. More problematically, it could add to the social proof that legal compliance is not necessary. Alternatively, the expressive role of law is relevant and potent in a society with a general perception in favor of compliance. Understanding how social proof manifests with reference to legal compliance also highlights mechanisms which can enable policymakers to generate social proof in favor of certain laws - or law in general — and considerably improve voluntary compliance to law.

This Article, most importantly, posits that no matter the variables one considers relevant in motivating individuals to comply with the law, one way our brain filters and weighs these informational inputs is by assessing the behavior of others. The informational inputs and the normative motivations are still as relevant. But how relevant these inputs are, their salience for our decision making, and their success in evolving our behavior, will be impacted—at least to some extent—by the behavior of those around us.

\section{B. Legal Uncertainty and Decision Making}

Most economic law scholars are unlikely to have knowledge of their exact rights and obligations under taxation law or the procedure to be followed under criminal code for filing an application to the court, despite working and having been trained in the legal field. The likelihood that any of us-even legal academics - read the "Terms of Use" contract before giving our consent on websites is very low. ${ }^{13}$ The goal of incorporating the changing interpretations of law through court judgments, executive decisions, amendments to the law, and legal knowledge seems even more

\footnotetext{
${ }^{13}$ Omri Ben-Shahar, The Myth of the "Opportunity to Read" in Contract Law (Univ. of Chi. L. \& Econ. Working Paper, Paper No. 415, 2008).
} 
challenging to attain. Yet, the legal literature often assumes perfect knowledge of law by the common man.

Within the legal literature, law is presumed to be both "widely known and understood."14 Consider the traditional neo-classical model of deterrence. ${ }^{15}$ To rationally determine whether one should or should not commit a crime, an individual should know: (a) the law, including the interpretation of the law, at the time of committing the act; (b) information about the probability of detection; (c) information about the duration and cost of trial; (d) information about probability of conviction; and (e) the likely severity of punishment. ${ }^{16}$

Is this presumption of "complete legal knowledge" a theoretical over-simplification like the "perfect information" assumption of economics? In Section B(I), this Article summarizes some empirical findings on how much information individuals are likely to possess about laws which directly impact them. Not surprisingly, the depth and clarity of legal knowledge is not adequate to explain compliance or non-compliance. In the second half of the section, this Article discusses how our brain uses social proof, in other words behavior of others, as informational proxies in situations involving incomplete information. As the experimental evidence provided suggests, this includes legal situations as well.

\section{Do We Know the Laws We Follow: Legal Knowledge and Compliance?}

For law to change behavior, one must know the law. The notion that legal knowledge is essentialboth to empower and deter individuals-is widely accepted. ${ }^{17}$ But how successful are states in disseminating legal information? When we consider legal awareness, what does that mean? Inquiring into whether there is legal awareness is an essential step between law and behavioral change that is often missed. More often than not, both compliance and non-compliance are presumed to be willful obeyance, or not, of the law. There exists a presumption of legal knowledge and an intention to comply with it when a driver stops at a red light. Could that not merely have been a consequence of the car in front stopping, or cross-traffic?

In 2008, a study conducted in Germany highlighted that only a third of the sample population had heard of the comprehensive workplace harassment law that had been passed two years prior, and another fifteen percent knew of-but not precisely what - the law set out. ${ }^{18}$ Similar results have been achieved in the United States and UK as well. ${ }^{19}$ Most people do not know the content of the laws or their procedures. An empirical study conducted on consumer protection laws and housing laws on English and Welsh citizens indicated that most individuals were not aware of their rights under the legislation. ${ }^{20}$ It was true irrespective of whether the law was more or less relevant to them-in other words between tenants and houseowners. Lack of legal knowledge is higher among individuals from more vulnerable socio-economic communities, like the poor or immigrants. ${ }^{21}$ This is problematic, especially considering how often governments rely on legal solutions to address socio-economic problems and empower the vulnerable.

\footnotetext{
${ }^{14}$ See, e.g., Steven Shavell, An Analysis of Causation and the Scope of Liability in the Law of Torts, 9 J. LEGAL STUD. 463,516 (1980). However, this Article argues that the assumption is frequent in any analysis which presumes without investigating about extent of legal information that compliance or non-compliance is a deliberate attempt at following or not following the law.

${ }^{15}$ Gary S. Becker, Crime and Punishment: An Economic Approach, 76 J. Pol. ECON. 169, 217 (1968).

${ }^{16} I d$.

${ }^{17}$ Lawrence M. Friedman, Impact: How Law Affects Behavior 14-26 (2016).

${ }^{18} I d$.

${ }^{19}$ Benjamin van Rooij, Do People Know the Law? Empirical Evidence about Legal Knowledge and Its Implications for Compliance, CAMBridge HaNDBOOK OF COMPL. (forthcoming 2021).

${ }^{20}$ Pascoe Pleasence, Nigel J. Balmer \& Catrina Denvir, Wrong About Rights: Public Knowledge of Key Areas of Consumer, Housing and Employment Law in England and Wales, 80 MoD. L. Rev. 836, 859 (2017).

${ }^{21}$ Lessig, supra note 11, at 969.
} 
It is abundantly clear, in studies as well as our own anecdotal experiences, that legal knowledge is not easily accessible by most individuals whose behavior it intends to impact. In a world with increasingly complex regulatory framework for governance, there seems to be a systemic misprediction about the content of the law by individuals governed by the law. ${ }^{22}$ This may be motivated by multiple reasons. It may be intentional to avoid cognitive dissonance between one's lived experiences and the law where the two diverge significantly. ${ }^{23}$ It may qualify as rational ignorance where the cost of acquiring the precise information is too high given the benefits. ${ }^{24}$ It can simply be lack of access to accurate and accessible information in a timely manner.

Questioning the assumption of perfect legal awareness of individuals is an important first step towards identifying what could motivate compliance or non-compliance to a law. If not always by directly learning about the law, how do individuals decide whether to comply with the law? In the next section, this Article aims to provide one such explanation of regulatory compliance in the presence of limited legal information-behavior of others within our social network.

\section{Deciding Under Imperfect Information Condition: A Cognitive Explanation}

Law is not unique in its dilemma as to how individuals decide between alternative behavioral choices under imperfect information conditions. Political science, economics, sociology, and psychology have all explored the issue from their own unique methodological prism. ${ }^{25}$ It requires an understanding of how our brain processes the limited information it has access to in order to arrive at conclusions. Decision theory-where an individual's informational and computational capacities is limited to the environment he exists in-was first academically explored at length by Herbert Simon in $1955 .{ }^{26} \mathrm{He}$ is credited for coining the term "bounded rationality," which provided an alternative modeling for decision-making where the mind utilizes the information and the structural information of their environment to arrive at an optimal decision. ${ }^{27}$

Recognizing that a legal agent's informational and computational capacities are limited aids in understanding why social perceptions about law and its enforcement become relevant. When faced with a decision, an individual - aware of their lack of complete information-relies on the behavior of others as a tool to help guide their own behavior. ${ }^{28}$ It results in what has been described by behavioral economists as "herding behavior." ${ }^{29}$ We have a natural tendency to trust decisions of others - and the reasons why others chose the behavior they chose is not always relevant for this impact. ${ }^{30}$ Movie and restaurant reviews, both online and in-person recommendations, are everyday examples of an individual's perception being impacted by the decisions of others. Literature on financial bubbles, trends, fashion fads, and marketing strategies all rely

\footnotetext{
${ }^{22}$ Sean H. Williams, Sticky Expectations: Responses to Persistent Over-Optimism in Marriage, Employment Contracts, and Credit Card Use, 83 Notre Dame L. Rev. 733, 791 (2009).

${ }^{23}$ See Robert C. Ellickson, Order Without Law: How Neighbors Settle Disputes (1990) (arguing that individuals were less likely to recognize legal rules if it contradicted with the folklore).

${ }^{24}$ Peter H. Aranson, Rational Ignorance in Politics, Economics and Law, 1 J. DEs ÉCONOMIsTES ET Des ÉtUdes HuMAINES 25, 42 (2014).

${ }^{25}$ See Joseph E. Stiglitz, The Contributions of the Economics of Information to Twentieth Century Economics, 115 Q. J. ECON. 1441, 1478 (2007) (outlining information economics and how it addresses information asymmetry in economic decisions); see also Edgar Kiser, Comparing Varieties of Agency Theory in Economics, Political Science, and Sociology: An Illustration from State Policy Implementation, 17 SOC. THEORY 146, 170 (1999) (articulating how sociology, political science and economics deals with information problems in principal-agent models).

${ }^{26}$ Herbert Simon, A Behavioural Model of Rational Choice, 69 Q. J. Econ. 99, 118 (1955).

${ }^{27} I d$.

${ }^{28}$ Shinji Teraji, The Cognitive Basis of Institutions: A Synthesis of Behavioral and Institutional Economics 40-45 (2018).

${ }^{29}$ John M. Keynes, The General Theory of Employment, Interest and Money 217 (1936).

${ }^{30}$ Abhijit V. Banerjee, A Simple Model of Herd Behavior, 107 Q. J. Econ. 797, 817 (1992).
} 
on aspects of social proof to explain frequently observed phenomena. ${ }^{31}$ Even popular media like "canned laughter" or marketing gimmicks like "the most popular or trusted brand" relies on the power of social proof. ${ }^{32}$

Utilizing others behavior around us as a proxy for missing information may be an active decision, such as when we arrive in a new country and are unsure of their civic processes, or when new traders rely on the behavior of seasoned investors to determine their investment strategy. ${ }^{33}$ This tendency to "imitate behavior" arises from an active acknowledgment by an individual about one's own lack of information. ${ }^{34}$ It acts as a proxy for all the information that the individual does not possess. Banerjee explained imitation, or, tendency to herd in stock markets, as a suspicion or expectation on the part of the individual player that the others may have certain private information that is not publicly accessible yet. ${ }^{35}$ When it is an active choice to utilize the behavior of others as an information proxy, it could, in theory, be easier to alter one's decision with accurate and updated information. Nonetheless, as this Article discusses in a later section, this may not always be possible in situations with network externalities and path dependencies. The instability and superficiality of fashion fads and financial bubbles are often explained through such easy shifts in decisions. ${ }^{36}$

More often than not, however, herd behavior, or following one's peers, constitutes part of our tacit knowledge-in other words we are more likely to intuitively know how to imitate rather than know why we imitate. ${ }^{37}$ It is a heuristic - or a cognitive shortcut - that our brain relies on to address situations. ${ }^{38}$ Gigerenzer and Goldstien described "imitation as the fast and frugal heuristic in social situations." ${ }^{39}$ It is more complicated to impact behavior with updated information when the decision is a result of a heuristic rather than an active decision.

Therefore, as individuals, the reason why we have a tendency to imitate the behavior of others around us is clear. It is a frequently chosen behavioral preference. When it comes to law, in its weakest assertion, this would imply that the behavior of others around us with respect to the law will have some impact on our decision to comply. The "behavior of others" in reference to the legal rule can inform our perception as to the effectiveness of the law and its implementation, what the precise law is, and so forth. At its strongest, we would replicate the behavior of others without considering the content of the law.

There have been multiple experimental studies to indicate how compliance with laws is impacted by social proof of others' compliance. Individuals are more likely to throw a scrap paper in the dustbin if they witness someone else doing the same soon before, or if the environment in which they are in is sufficiently clean. ${ }^{40}$ People tend to comply with tax laws better if they perceive that others within their tax bracket are also complying with the law. ${ }^{41}$ People spend more effort

\footnotetext{
${ }^{31}$ Sushil Bikhchandani, David Hirshleifer \& Ivo Welch, Learning from the Behavior of Others: Conformity, Fads, and Informational Cascades, 12 J. ECON. PERSP. 151, 170 (1998).

${ }^{32}$ Robert B. Cialdini, Influence: Science and Practice (1993).

${ }^{33}$ David Hirshleifer \& Siew Hong Teoh, Herd Behaviour and Cascading in Capital Markets: A Review and Synthesis, 9 EuR. Fin. Mgmt. 25, 66 (2003).

${ }^{34}$ John M. Keynes, A Treatise on Money (1930).

${ }^{35}$ Banerjee, supra note 30, at 817; Hayagreeva Rao, Henrich R. Greve \& Gerald F. Davis, Fool's Gold: Social Proof in the Initiation and Abandonment of Coverage by Wall Street Analysts, 46 ADMIN. SCI. Q. 502, 526 (2001).

${ }^{36}$ Bikhchandani, Hirshleifer \& Welch, supra note 31.

${ }^{37}$ Riccardo Viale \& Andrea Pozzali, Cognitive Aspects of Tacit Knowledge and Cultural Diversity, in MODEL-BASED Reasoning in Science, Technology, And Medicine 229, 229 (Lorenzo Magnani \& Ping Li eds., 2007).

${ }^{38}$ Michelle C. Baddeley, Herding, Social Influence and Economic Decision-Making: Socio-Psychological and Neuroscientific Analyses, 365 Phil. Transactions Royal Soc'y 281, 290 (2010).

${ }^{39}$ Gerd Gigerenzer \& Daniel G. Goldstein, Reasoning the Fast and Frugal Way: Models of Bounded Rationality, 103 PsyCH. REV. 650, 669 (1996).

${ }^{40}$ Cass R. Sunstein, Social Norms and Social Roles, 96 Colum. L. Rev. 903 (1996).

${ }^{41}$ Steven M. Sheffrin \& Robert K. Triest, Can Brute Deterrence Backfire: Perceptions and Attitudes in Taxpayer Compliance, in Why People Pay Taxes: Tax Compliance and Enforcement 193, 212 (Joel Slemrod ed., 1992) (finding that "tax gap"
} 
returning a lost wallet if they are informed that someone else did so too. ${ }^{42}$ How seriously one perceives the risk of marijuana consumption in states where it is illegal, or how seriously one perceives the risk of underage drinking, largely depends on the social proof they receive from peers around them. ${ }^{43}$

These are examples where there is a greater focus on informational social influence or social proof. Though there may be elements of normative social influence as well-one may be likely to consume certain substances if they believe it helps them "fit better" in the group. However, it still does not take away from the informational social influence with respect to the law, in other words it is clearly safe to consume a substance despite its illegality, if no one around seems to suffer any legal consequences.

There is an additional social influence often ignored in our theoretical discussions on legal compliance but frequently highlighted in empirical investigations. Legal compliance is not always binary, neither is knowledge of law. ${ }^{44}$ When an individual provides in a survey that they know of "sexual harassment laws," does it imply they know what "sexual harassment" means under the law? Studies indicate that most people who are aware of a law often fill in the details of the law in accordance with their own understandings of "what they think is legal or illegal." In a recent empirical study on what employees thought constituted "sexual harassment" under law, unsurprisingly, the interpretation was dependent on an individual's personal perception as well as social interactions in workplace. ${ }^{45}$ In family law, a survey done in the United States indicated that individuals interpreted "parental responsibility" to mean who gets property in the instanc e of an unplanned death of a spouse, the differences in responsibility under legal cohabitation, and the legalities surrounding marriage. ${ }^{46}$ Multiple studies have similarly concluded across disciplines, such as criminal and employment law, that the individual expectations of what the law says is more closely aligned with the social attitude - and their expectations - of what the law ought to say, rather than what it actually says. ${ }^{47}$ Behavior of those around us provides us with both informational and normative evidence as to how we interpret the laws we hear. Therefore, we utilize the behavior of others around us not only to decide whether or not to comply with a law but also to determine what compliance means.

So far, this Article follows, to some extent, the explanation put forward by the social influence conception of deterrence - that observing behaviors of others can influence our decisions. In fact, it extends the scope of informational social influence beyond criminal law to policy at large. Nonetheless, to conclude that developing the understanding of social proof here would be a problematic over-simplification of the complex socio-cognitive phenomenon. In the next section, this

stories can spark greater evasion even when information about noncompliance is combined with publicity of stepped up enforcement efforts); John T. Scholz, Kathleen M. McGraw \& Marco R. Steenbergen, Taxpayer Adaptation to the 1986 Tax Reform Act: Do New Laws Affect the Way Taxpayers Think About Taxes, in Why PeOPle PAy TAXEs: TAX COMPLIANCE AND ENFORCEMENT 9-37 (Joel Slemrod ed., 1992) (noting that opinions towards taxation of persons whom a taxpayer interacts with exert a greater influence on compliance rate than economic consequences of taxation on a taxpayer).

${ }^{42}$ Sarah-Jeanne Salvy, Eric R. Pedersen, Jeremy N.V. Miles, Joan S. Tucker \& Elizabeth J. D’Amico, Proximal and Distal Social Influence on Alcohol Consumption and Marijuana Use Among Middle School Adolescents, 144 DRUG \& AlCOHOL DEPENDENCE 93, 93-101 (2014).

${ }^{43} I d$.

${ }^{44}$ FrIEDMAN, supra note 17 , at 44-72.

${ }^{45}$ Justine E. Tinkler, People Are Too Quick to Take Offense: The Effects of Legal Information and Beliefs on Definitions of Sexual Harassment, 33 LAW \& SOC'y INQUIRY 417, 417-45 (2008).

${ }^{46}$ Pascoe Pleasence \& Nigel J. Balmer, Ignorance in Bliss: Modeling Knowledge of Rights in Marriage and Cohabitation, 46 LAW \& SOC'Y REV. 297 (2012).

${ }^{47}$ See Anne Barlow, Simon Duncan, Grace James \& Allison Park, Cohabitation, Marriage and the Law: Social Change and Legal Reform In the 21st Century (2005); see also John M. Darley, Kevin M. Carlsmith \& Paul H. Robinson, The Ex Ante Function of the Criminal Law, 35 LAw \& Soc'Y Rev. 165, 165-89 (2001); see also Pauline Kim, Norms, Learning, and Law: Exploring the Influences on Workers Legal Knowledge, 2 U. ILL. L. REV. 447, 447-515 (1999). 
Article develops the concept of how social proof manifests within a society. It operationalizes the concept within a society and in the context of legal compliance.

\section{What Constitutes "Social Proof of Legal Compliance" for Individuals}

The question of what the elements are of "social proof" for an individual is an essential question to understanding its impact on legal compliance and also in establishing the limits of the theory? One should avoid the fallacy of equating social proof as a cognitive explanation or argument for simplistic trust in majoritarianism. Not all opinions are equal for our brains. Therefore, it is important to understand whose behavior we look at, what behaviors are relevant for inferring certain legal information, how much evidence one needs to form their opinions and perceptions, and also what is the nature of informational social influence that can persuade our minds in favor of or against a decision. This section details the relevant variables one must consider when discussing a social proof explanation to legal compliance.

\section{Group Identities: Who Matters?}

Individual belief and perception of the world are acquired not by independent verification of the facts in the real world, but from social sources regarded as legitimate. ${ }^{48}$ This section of the Article deals with what individuals are likely to consider legitimate social sources. Cialdini summarized it best in his "Rules of Persuasion"- - people listen to others like them. ${ }^{49}$ Therefore, the initial explanation for our behavior that this Article begins with, that "everyone else was doing it," is often simply "everyone else around me was doing it."

It is simple and intuitive. Our mind cannot process behaviors it does not observe-including those outside of our social network. This notion is also supported through multiple experimental studies. Studies show that young people are more likely to disregard the choices of older people. ${ }^{50}$ In a study, New Yorkers were more likely to embark on a more serious attempt to return wallets when they were informed that another New Yorker had attempted to do so-as compared to New Yorkers being informed that another foreigner had made similar attempts. ${ }^{51}$ It is, therefore, important to understand that social proof is not always synonymous with trusting the majority. The trust will more strongly be placed on the social network that one relies on or identifies with. ${ }^{52}$

The relevant social network, in fact, evolves for each of us as the nature of law and relevant behavior changes. When faced with a decision, the individual will categorize the problem based on its salient characteristics — as the individual identifies them in a given situation-and this categorization will help identify the social group relevant for deciding, enabling the individual to arrive at his conclusion on how to act, based on a comparison of the popular belief within the identified group. ${ }^{53}$ The group may vary depending on the categorization of the decision type. For example, on how strictly to adhere to an office dress code, the behavior of co-workers is more relevant. And while deciding on whether to segregate the garbage, the behavior of those we share community bins with becomes more relevant. Accordingly, there is no one monolithic group relevant for social proof. ${ }^{54}$ In a study conducted to observe energy consumption, it was observed that

\footnotetext{
${ }^{48}$ Simon, supra note 26 , at 202.

${ }^{49}$ CiAldini, supra note 2.

${ }^{50}$ May Sudhinaraset, Christina Wigglesworth \& David T. Takeuchi, Social and Cultural Contexts of Alcohol Use: Influences in a Social-Ecological Framework, 38 AlcoHol Res. 35, 35-45 (2016).

${ }^{51}$ Robert B. Cialdini, Harnessing the Science of Persuasion, 10 HARV. Bus. REV. 72, 72-79 (2001).

${ }^{52}$ Russell Spears, Group Identities: The Social Identity Perspective, in HANDBOOK OF IDENTITY THEORY AND RESEARCH. (Seth J. Schwartz et al. eds., 2011).

${ }^{53}$ Cristina Bicchieri, Habits of the Mind, in The Grammar of Society: The Nature and Dynamics of Social Norms 55, 55-99 (2012).

${ }^{54}$ Samara Klar, The Influence of Competing Identity Primes on Political Preferences, 75 J. PoL. 1108, 1108-24 (2013).
} 
households adjusted their consumption when information was shared about the energy consumption of their neighbors. ${ }^{55}$ For this decision, households within the community constituted the relevant social group irrespective of how close-knit a community was.

Identities are fluid and change according to situations and context. In fact, the sense of group identity and the instinct to mimic behavior can even be artificially influenced. Experiments indicate that subtle priming, where certain characteristics of groups are highlighted by the experimenter, can cause individuals to imitate or align their behaviors with others possessing such characteristics despite not necessarily sharing strong group identities with these individuals outside of the experiment. ${ }^{56}$ These types of "identity priming" techniques are often utilized in policy debates by framing issues around group identities where individuals are more likely to agree or disagree with a given policy stance when one changes the group that constitutes the relevant social network for influence. ${ }^{57}$ Research indicates that merely mentioning an identity increases the salience of the interests and behavioral preferences of that group-thereby making it the relevant sample for social proof-without any specification on how such policies or laws impact that group. ${ }^{58}$

Similarly, there are experiments where spontaneous groups are randomly selected, and although these groups are not natural groups, they still exhibit stronger tendency of behavior alignment within these artificial groups. ${ }^{59}$ Once a group identity is created, there is a stronger tendency to imitate, even in the absence of a cohesive group identity. ${ }^{60}$

These are important nuances to social proof that should be of importance for law makers and regulators: (a) people look at people like themselves to form their own perception of the law; (b) the identity of "self" is transient and differs in different contexts; and (c) different identities of the self can be triggered in different situations, which may create completely different behavioral responses, despite adhering to the principle of social proof.

This has some direct repercussions on legal compliance. From a policy standpoint, the individuals relevant for determining one's social proof of compliance also help determine how to effectively focus resource allocation for increased compliance. First, it highlights that localized information dissemination with local examples of successful compliance and enforcement are more likely to be successful than nation-wide advertisement campaigns-especially in larger countries with diverse populations and stronger group identities. ${ }^{61}$ Recent comparative empirical research on compliance in weak state situations highlights how weak states-meaning states with limited capacity for traditional enforcement_can in fact considerably increase compliance by adopting effective strategies of legal knowledge dissemination. ${ }^{62}$

Second, it highlights that one effective means of disseminating legal information given our discussion on the role of reference networks is through exemplifying local examples. Local examples of compliance and non-compliance as well as associated consequences influences our perception in two ways. First, it provides us with more information, directly reducing informational uncertainty. Second, it alters our existing information by altering the information received through

\footnotetext{
${ }^{55}$ Ian Ayres, Sophie Raseman \& Alice Shih, Evidence from Two Large Field Experiments that Peer Comparison Feedback Can Reduce Residential Energy Usage (Nat'l Bureau Econ. Rsch., Working Paper No. 15386, 2009).

${ }^{56}$ Ali M. Ahmed, Group Identity, Social Distance and Intergroup Bias, 28 J. Econ. PsycH. 324, 324-37 (2007).

${ }^{57}$ Amos Tversky \& Daniel Kahneman, Belief in the Law of Small Numbers, 76 PsYCH. BulL. 105, 105-10 (1971).

${ }^{58} \mathrm{Klar}$, supra note 54.

${ }^{59}$ TerajI, supra note 28.

${ }^{60}$ Patrick Bourgeois \& Ursula Hess, The Impact of Social Context on Mimicry, 77 BIOLOGICAL PsyCH. 343, 343-52 (2008); Yanelia Yabar, Lucy Johnston, Lynden Miles \& Victoria Peace, Implicit Behavioral Mimicry: Investigating the Impact of Group Membership, 30 J. Nonverbal Behav. 97, 97-113 (2006).

${ }^{61}$ Susan L. Ostermann, Regulatory Pragmatism, Legal Knowledge and Compliance with Law in Areas of State Weakness, 53 L. \& Soc'Y REV. 1132, 1132-66 (2019).

${ }^{62} I d$.
} 
social proof. Witnessing increased compliance to traffic laws in urban areas, in general, or another city has little influence on one's decision to comply with the law. Similarly, discussing the benefits of legal compliance or the potential harm from non-compliance is less forceful if those around an individual are often, and without consequence, ignoring the law.

Does this discussion suggest that there should be high levels of compliance across all identifiable groups to reach the "everyone" in "everyone is doing so?" How many individual cases of compliance within one's group constitute sufficient evidence for "social proof?" The following section discusses what our brains need to form their own conclusions in terms of the quantity and quality of "social proof."

\section{Law of Small Numbers and Availability Heuristic: How Many People Are Needed to Persuade Us?}

Another way in which our brains manage deciding with limited information is through its tendency to generalize from small sample spaces. It is a cognitive fallacy when we presume a small set of examples are representative of a much larger set, sometimes even the entire population. ${ }^{63}$ For our purposes, this Article assumes that very limited experiences of our own, if within our social network, are sufficient for us to conclude the efficacy of the legal system and the usefulness of the specific law or even laws in general-regardless of whether or not most individuals comply with the law. This number can be as small as one. Consider how often we have heard explanations for decisions starting with "I heard someone did/say . . . ." ${ }^{64}$ The causal jump from "someone/some people are doing so" to "everyone/most people must be doing so" is made by our cognitive ability to generalize, even from an unrepresentative and small sample of information.

Therefore, the number of responses one observes before deciding to emulate the behavior of his peers could be a very small number. But whose behavior is more relevant and what choices play a more important role in forming an individual's perception of "what people do" is impacted by another cognitive limitation of our brains - the availability heuristic. The availability heuristic refers to the excessive weightage our brain associates with more easily retrievable or recent memories and information. ${ }^{65}$

Considerable empirical work on how availability heuristics impact decisions was conducted in risk studies. In a famous empirical study where the risk perceptions of individuals were evaluated, the presence of availability heuristic through media coverage of different incidents in decisionmaking was strongly observed. ${ }^{66}$ Eighty percent of individuals considered accidental deaths to be more deadly than strokes even though strokes cause twice as many deaths. Tornadoes were considered more dangerous than asthma even though the latter kills twenty times more people. Death by an accident was considered 300 times more likely than death by diabetes, even though diabetes caused four times the number of deaths than accidents. The study concluded that events which were given greater media coverage were considered more likely to occur than not. For social proof, the study implied that scandals within the community would be more likely to be remembered.

The availability heuristic implies that we are likely to ignore the actual probability of something happening in favor of the few incidents we do remember. Cass Sunstein, in his analysis of policies on terrorism termed the phenomenon of "probability neglect," argued that there is a stronger tendency of public mobilization and demand for regulation of emotionally charged issues, even

\footnotetext{
${ }^{63}$ Tversky \& Kahneman, supra note 57.

${ }^{64}$ Thomas Gilovich, How We Know What Isn't So: Fallibility of Human Reason in Everyday Life 29-48 (1991).

${ }^{65}$ George F. Loewenstein, Elke U. Weber, Christopher K. Hsee \& Ned Welch, Risk as Feelings, 127 PsYCH. BULL. 267, 267-86 (2001).

${ }^{66}$ Sarah Lichentenstien, Paul Slovic, Baruch Fischoff, Mark Layman \& Barabara Coombs, Judged Frequency of Lethal Events, 4 J. EXPERIMENTAL PSYCH. 551, 551-78 (1978).
} 
if there are more urgent and relevant policy matters with lesser emotional appeal. ${ }^{67} \mathrm{He}$ considered it to be a manifestation of the availability heuristic. As we tend to remember more strongly incidents that are associated more closely with certain emotions, we are more emotionally invested in issues that are more likely to suffer from probability neglect. ${ }^{68}$

Understanding the availability heuristic is essential for the theory of social proof because that initial "I heard someone did/say ..." explanation for our behavior is more likely to be guided by a memory or story which happened to someone close to us, was highly publicized, or emotionally impacted us. Between national data on corruption and a recent experience of a sibling successfully bribing a police officer, the latter is more likely to inform an individual's decision on whether one should offer up a bribe to a traffic warden for not wearing a seat belt. If an individual successfully bribes an officer or hears about such corruption from peers, it is more likely to color one's own perception of legal accountability of government servants than any available statistics on improving accountability of the legal institutions.

The cognitive abilities of our brain to give more weight to individual events over statistical probabilities provides resource-strapped countries with an alternative solution on how to improve perception of stronger legal enforcement by publicizing incidents of local enforcement. This would effectively involve individuals who are central to various social networks and equipping them with adequate information. Any information received through these people and platforms is more likely to leave a lasting memory than generic legal advertisements. Decentralizing legal information dissemination and creating public examples are key to creating a perception of compliance.

In a dynamic equilibrium, these perceptions could create a self-fulfilling cycle, where the perception of law determines the success or failure of the law and each of these successes or failures further entrenches the perception of the law. This cascading effect of social proof across the society and across multiple laws is discussed in the following section.

\section{Social Proof Within a Dynamic Equilibrium: Informational Cascades and Network Effects Creating "Perception of Law" Within Societies}

So far, this Article explains how "because people do so" could impact our own decisions to comply with a law. It also argues that "people do so" often implicitly means "my friends/family do so" or even, more narrowly, "I heard/know of someone who did so . . .." In this section, this Article explains how small numbers of such "I heard/know of someone who did so" incidents can create widespread compliance, or non-compliance, through informational cascades about a legal rule, as well as generalized perception in favor of or against legal compliance at large.

\section{Informational Cascades Within a Law}

If enough people believe that other people do something, enough people will do the same thing over time. The initial mistaken belief comes to indicate the reality over time as a self-fulfilling prophecy. In fact, to explain the term "self-fulfilling" prophecy, Robert Merton, who is credited for coining the phrase, used an illustration involving informational social influence itself-the actual collapse of a bank because the bank's customers feared the bank was collapsing. ${ }^{69}$

The principle of social proof suggests that we are influenced by the behavior of those around us even in the absence of any normative motivations. But unlike an academic who analyzes patterns ex-post, most individuals cannot observe the behavior of the aggregate in real time or predict

\footnotetext{
${ }^{67}$ Cass R. Sunstien, Terrorism and Probability Neglect, 26 J. RisK \& UNCERTAINTY 121, 121-36 (2003).

${ }^{68}$ Amos Tversky \& Daniel Kahneman, Judgment Under Uncertainty: Heuristics and Biases 11-14 (Daniel Kahneman, Paul Slovic \& Amos Tversky eds., 1974).

${ }^{69}$ Robert K. Merton, The Self-Fulfilling Prophecy, 8 ANTIOCH REV. 193, 193-210 (1948).
} 
which behavior will turn out to be the dominant pattern within their social network. Our decisions are made on the basis of following some decisions that we have observed, known of, or heard about, in a situation similar to ours. These experiences can be a product of our past experiences and are not always associated precisely with the law in question. Adding to the previously discussed availability heuristic and representative biases, a few decisions can come to form our perception of "how things are done" in a society. Once we extrapolate the behavior of the few to represent social opinion and follow the decision, we become part of the social proof for others around us. If enough people similarly extrapolate decisions of a few around them, the extrapolation becomes reality, meaning the decision of the initial few empirically represents the choice of the majority within that society.

There is uniformity in behavior which will propel future behavioral compliance in accordance with the principle of social proof. Nevertheless, the initial uniformity itself was also a consequence of the cognitive tendency to imitate. This creates a cyclical pattern where there could be constantly high levels of compliance with an inefficient private behavior based on the initial decisions of very few participants which resulted in a cascade. Marketing research often utilizes information cascades as an explanation for fashion fads and trends.

The most prominent exploration of this cascading impact of social influence on regulation was provided by Cass Sunstein and Timur Kuran. ${ }^{70}$ They considered social influences-both informational and normative - on increased perception of risk from certain threats, such as terrorism or illegal immigration, after some tragic events and the resultant emphasis on spending state resources on regulating probabilistically fewer threatening issues while ignoring other relevant issues. They argued that "public discourse shapes individual risk judgments, risk preferences, and policy preferences; and the reshaped personal variables then transform the public discourse that contributed to their own transformations." Such behavior creates a cyclical feedback loop.

This Article applies this feedback loop within our discussion on the informational social influence on legal compliance. Initial individual decisions to comply or not comply based on small sample spaces of compliance or non-compliance they see around them will create a widespread cascading effect, increasing the strength of the social proof. The belief that most people follow the law will create the evidence to morph the belief into a self-fulfilling, reinforcing behavior in favor of or against compliance in the long run. A strong correlation between initial impression of individuals about general compliance and their own decision on compliance has been observed both in randomized and lab experiments. ${ }^{71}$ This Article uses social proof and information cascades to explain this frequently observed social behavior and its impact on our understanding of compliance.

As a social phenomenon, it requires a few initial takers to create widespread uniformity in behavior. ${ }^{72}$ Informational cascades can be propelled through herding tendencies of humans even when there is no direct effect of the decisions of others on one's own payoffs, meaning the only externality of one's decision in these circumstances are informational in nature. ${ }^{73}$

\footnotetext{
${ }^{70}$ Cass R. Sunstein \& Timur Kuran, Availability Cascades and Risk Regulation, 51 STAN. L. ReV. 683 (1999).

${ }^{71}$ See Christoph Engel, Martin Beckenkamp, Andreas Glöckner, Bernd Irlenbusch, Heike Henning-Schmidt, Sebastian Kube, Michael Kurschilgen, Alexander Morell, Andreas Nicklisch, Hans-Theo Horrmann \& Emanuel Towfigh, First Impressions are More Important Than Early Intervention: Qualifying Broken Windows Theory in the Lab, 37 INT'L REV. L. \& ECON. 126, 126-36 (providing a broad literature review of experimental evidence from across multiple jurisdictions); Philip Zimbardo, The Human Choice. Individuation, Reason, and Order Versus Deindividuation, Impulse, and Chaos, 17 Neb. Symp. Motivation 237, 237-307 (1969); Hope Corman \& Naci Mocan, Carrots, Sticks, and Broken Windows, 48 J.L. \& ECON. 235, 235-66 (2005).

${ }^{72}$ See Bogaćhan Ćelen \& Shachar Kariv, Distinguishing Informational Cascades from Herd Behavior in the Laboratory, 94 AM. ECON. Rev. 484, 484-98 (2004) (distinguishing the two manifestations of imitative behavior, in other words herding and informational cascades).

${ }^{73}$ Bikhchandani, Hirshleifer \& Welch, supra note 31, at 151-70; Ivo Welch, Sequential Sales, Learning, and Cascades, 47 J. Fin. 695, 695-732 (1992); Banerjee, supra note 30, at 817.
} 
However, in the real world, there are network effects to social learning as well-our own payoffs may be dependent on how many others follow the trend. ${ }^{74}$ Consider financial markets-if one buys shares in a company based on a portfolio of successful investors, the bet is that enough other investors will have the tendency to imitate the behavior of successful investors to increase the prices and earn profits. The expectation that others will follow a trend will itself create or break the momentum for the trend to imitate. ${ }^{75}$

These network effects, often, exist for even smaller legal compliances. Consider stopping at a traffic light. On arriving in a new city or as an inexperienced driver, my decision to stop at a red light will depend on the first few drivers I witness - or on how I saw other drivers behave when I was younger. If these individuals chose not to stop at the red light, neither would I. I would also not expect the driver in front of me to do so. In fact, in such matters requiring coordination, it is better if I followed the people around me and not the law. ${ }^{76}$ Further, there is a self-reinforcement of availability. As the number of people imitating a social behavior increases, there exists more evidence to convince others that there must be a reason as to why "so many" people are doing what they are doing. Even in the absence of such normative faith in the actions of the people, in such coordinated situations, law is only as useful as the expectation that those around will comply with the law. If the social proof contradicts this presumption of compliance, our brain will update its behavior. Consider rules on jaywalking in India, United States, France and Germany. Most countries have rules against it but our behavior as pedestrians is dependent on those around us, and rightly so.

Following this explanation for legal compliance and the example above, there is an important observation to be made about the instrumental functions of law. These include the ability of laws to signal to society normative attitudes of acceptable behavior and focal points around which to coordinate behavior. ${ }^{77}$ They are often considered reinforceable independent of the traditional compliance techniques required for behavioral change. ${ }^{78}$ However, if the observable social proof is of non-compliance to the law, it is unlikely to signal any new focal points for coordination or change in normative social attitudes. This is so because, given the expectation of non-compliance, no one will be willing to be the first law-complying individual required to propel a cascade. ${ }^{79}$ There are two ways to address the issue. First, creating initial proof in favor of compliance through traditional legal compliance strategies. Second, relying on a general empirical expectation in favor of legal compliance. Creating initial proof in favor of compliance through traditional enforcement mechanism means people will evolve their expectation based on the new information they receive. Another approach which enables the early compliant behaviors in light of new law is an empirical expectation in favor of compliance-in other words, an expectation that most people will, unless it is against their interest, follow a new law when informed about it.

Given our discussion on the importance of early compliant behaviors in initiating compliance cascades, understanding what these empirical expectations are is relevant to our discussion. The following discussion explains how social proof transmutes between legal rules and can affect the overall perception towards legal compliance.

\footnotetext{
${ }^{74}$ Mathias Drehmann, Jörg Oechssler \& Andreas Roider, Herding With and Without Payoff Externalities: An Internet Experiment, 25 INT'L J. INDUS. ORG. 391, 391-415 (2007).

${ }^{75}$ Hirshleifer \& Teoh, supra note 33, at 66.

${ }^{76}$ See Kaushik Basu, The Republic of Beliefs: A New Approach to Law and Economics (2018).

${ }^{77}$ MCADAMS, supra note 10.

${ }^{78}$ See Maggie Wittlin, Buckling Under Pressure: An Empirical Test of the Expressive Effects of Law, 28 YALE J. ON REG. 420, 420-59 (2011); Patricia Funk, Is There An Expressive Function of Law? An Empirical Analysis of Voting Laws with Symbolic Fines, 9 AM. L. \& ECON. Rev. 135, 135-59 (2007).

${ }^{79}$ Needless to say, the problem will not arise in situations where members of a society were sticking to a behavioral pattern out of normative social influence-such as fear of reputational sanction-exclusively. These outliers will happily comply with the law to provide the requisite initial social proof for a subsequent cascade, given they fulfil the previously discussed characteristics of adequate social proof.
} 


\section{Information Cascades Across the System: Perception of Compliance}

So far, this Article outlines how observable decisions of even a few within our social network can result in widespread compliance or non-compliance with a rule, thereby communicating a persistent perception in favor of or against voluntary compliance to that legal rule. Nonetheless, this perception will not always be limited to individual illustrations of compliance or non-compliance and specific rules. The cognitive tendency to generalize from a small sample-law of small numbers - to a wider population applies also to generalizing from witnessing compliance or non-compliance of a few rules to the operation of that general legal system as well. Similarly, the informational cascade previously discussed in reference to a few individuals influencing widespread compliance also flows from experiences with a few rules to many and, over time, to our general perception about the legal system at large. For example, social proof about following traffic lights will also inform our decision on whether to comply with a newly introduced rule about putting on seat belts. Similarly, based on the stories and experiences of others in our reference network, our response to a police officer requesting us to pull over will be impacted irrespective of whether we are stopped for driving under influence, not wearing a seat belt, or texting while driving.

For legal systems, social proof can contribute to shaping two perceptions: (a) perceptions about the efficacy and need of legal compliance-or subject-matter specific perception-based on witnessing others interacting with some rules; and (b) perception about procedural fairness of legal actors within a system - or procedural or process specific perception-based on witnessing or hearing others interacting with different legal actors. There is also a strong level of interconnectivity between the perception of the procedure and perception of the effectiveness of the laws with studies showing that when people perceived the legal procedures followed by different legal actors, there was stronger presumption of fairness of legal rules and greater likelihood of voluntary compliance. ${ }^{80}$ In this case, individuals utilized their own experiences and experiences of their peers with legal authorities as informational proxies for all the legal information missing with respect to the content of the various legal rules.

Similarly, studies conducted on perception of local courts among people in the United States indicate that people who do not have direct experience with the court system use their perception of the government, in general, to evaluate their local courts. ${ }^{81}$ In the absence of experience and information about the judicial system, individuals relied on their own and others' experiences of interacting with governmental agencies to develop their perceptions of the courts.

Therefore, our cognitive tendency to rely on the behaviors of others creates two types of informational cascades in reference to regulatory compliance. One is an informational cascade within a single law which results in widespread compliance or non-compliance to the legal rule from a small behavior set, which can result in widespread compliance or non-compliance. The other is between laws where social influence of compliance to some rules guide behavior in compliance with other rules. Taken together, this can create a socio-behavioral loop in favor of or against compliance with certain laws. This in turn contributes to a general perception of law at large. The general perception of legal rules and law at large, furthermore, guides future individual decisions on compliance. Therefore, there is constant reinforcing feedback between individual behavior and widespread compliance through the intermediating impact of informative social influence.

Considering social proof within this dynamic equilibrium across rules helps identify an important shortcoming in the existing legal literature on informational social influence. Visibly reduced disorder in a neighborhood will have an impact on the individual's perception about criminality. Despite this, it will not exclusively have an impact on the perception of the individual.

\footnotetext{
${ }^{80}$ See Tom R. Tyler, Why People Obey the Law (1990); see also Jason Sunshine \& Tom R. Tyler, The Role of Procedural Justice and Legitimacy in Shaping Public Support for Policing, 37 LAW \& Soc'y Rev. 513, 513-48 (2003).

${ }^{81}$ Susan M. Olson \& David A. Huth, Explaining Public Attitudes Toward Local Courts, 20 JUST. Sys. J. 41, 41-61 (1998).
} 
The perception about the government, legal actors, and the procedure followed will also impact deterrence. Most importantly, the general perception within the society about law and legal compliance at the time when these new policing policies are introduced will influence how this new information is perceived. If the general perception about law and legal compliance is negative, given the presumed disorderliness, the indiscriminate and harsh policing mechanisms introduced for law-and-order maintenance are more likely to create a negative perception about police legitimacy. There is increasing empirical evidence to support this presumption. ${ }^{82}$ Given the explanation of informational cascades between rules - including procedural to substantive laws - there arises the implication that strategies, when applied in isolation, can push the perception against voluntary compliance rather than towards it. In fact, there is some scattered empirical evidence to support this assertion. ${ }^{83}$

This cognitive explanation of legal compliance both emphasizes and is emphasized by literature on legal socialization. Legal socialization refers to the process of acquiring the requisite norms, values, and behavioral models for interacting with law and legal authorities by children through assimilation and adaptation of the information they receive from their surroundings. ${ }^{84}$ It focuses on building the accurate or desired perception of law and legal authorities at an early age as it recognizes the reinforcing nature of social learning. Empirical research on legal socialization in adolescents also lends credence to the fact that perceptions, once created, become the filter through which future decisions on compliance will be taken. ${ }^{85}$ Literature on legal socialization and an individual's interaction with law has also emphasized the role that the society one lives in, including the observable behavior of others-social proof-plays an important role in giving direction to this legal socialization. ${ }^{86}$ The behavior of others includes within it the observable behavior of legal actors. ${ }^{87}$ Therefore, the discussion on cascading across laws and the importance of perceived procedural fairness in creating compliance cascades cannot be undermined.

Recently, the United Nation released a document recommending "strengthening the rule of law through education." 88 It advocates for teaching a culture of lawfulness by imparting basic legal knowledge and enforcing positive compliance behaviors in school. The document is a policy document which aims to formalize a favorable legal socialization mechanism. Social and environmental factors cannot be absolutely compensated through a school's curriculum, but it is an essential first step in breaking a persistent negative perception and non-compliance self-enforcing equilibrium. Legal socialization in childhood will equip the individuals with what Christopher Engel described as "normative proficiency" in law-in other words, the ability to handle normative expectations. Over time, different declarative knowledge — what should be done or not done-will be acquired through specific laws. ${ }^{89}$

Once there exists a general perception in favor of compliance-or, normative proficiencyindividuals are more likely to presume or expect compliance when new laws are introduced. And, as this Article posited in the beginning of this section, if enough people believe that others will do something, enough people will do that thing over time.

\footnotetext{
${ }^{82}$ See generally Bernard E. Harcourt, Illusion of Order: The False Promise of Broken Windows Policing, 43 BRIT. J. CRIM. 446 (2003) (critiquing the broken window theory).

${ }^{83}$ Jeffrey Fagan \& Tom R. Tyler, Policing, Order Maintenance and Legitimacy, in POLICING IN CENTRAL AND EASTERN Europe: Dilemmas of Contemporary Criminal Justice (Gorazd Mesko et al., eds., 2004); Jacinta M. Gau \& Rod K. Brunson, Procedural Justice and Order Maintenance Policing: A Study of Inner-City Young Men's Perceptions of Police Legitimacy, 27 Just. Q. 255, 255-79 (2010).

${ }^{84}$ Chantal Augven, Legal Socialisation: From Compliance to Familiarization Through Permeation, 1 EUR. J. LEGAL STUD. 265 (2007).

${ }^{85}$ Jeffrey Fagan \& Tom R. Tyler, Legal Socialization of Children and Adolescents, 18 Soc. Just. Res. 217, 217-41 (2005).

${ }^{86}$ Clifford Geertz, Thick Description: Toward an Interpretive Theory of Culture, in The INTERPRETATION OF CULTURES: Selected Essays 3, 3-30 (1973).

${ }^{87}$ Fagan \& Tyler, supra note 83.

${ }^{88}$ Unesco, Strengthening the Rule of Law Through Education: A Guide for Policymakers (2019).

${ }^{89}$ Christoph Engel, Learning the Law, 4 J. INST. ECON. 275, 275-97 (2008).
} 


\section{E. Limitations of the Explanation and Scope for Future Research}

The informational limits within which individuals make their legal decisions everyday highlights an urgent need to update the assumption of perfect legal knowledge within legal literature. Once we recognize the imperfect information conditions within which legal subjects operate, it enables legal research and policy to more accurately explain and predict how a regulation will manifest in practice. If we do not know precisely what the law is, how will we choose whether to comply or not comply with the law? The social proof theory of compliance is one such explanation of widespread compliant or non-compliant behavior in societies with respect to certain laws. Applying cognitive heuristics of availability and representativeness explains how our brain can generalize from a small number of observed behaviors. In addition, the information cascades within and across laws explain how these small number of behaviors, over time, result in widespread compliance or non-compliance cascades.

By focusing on how our brains process relevant information for legal compliance rather than explaining what relevant information law and legal enforcement should communicate to individuals - theories of legal compliance are bolstered rather than contradicted. Individuals could be complying with specific laws because of the sanctions or the economic incentives. It could be because the law provides a focal point for coordination or because it expresses a normative attitude of the society. Irrespective of the motivation, a cognitive filter through which the informational input will flow, resulting in the behavioral output of compliance or non-compliance, will be that of social proof. For example, it is not the actual probability of sanctions or incentives that motivates individuals, but the perceived risk of sanctions or the perceived gain. One piece of evidence that we utilize to form our perceptions about these variables is through the social proof of the behavior around us.

This also highlights an important limitation of this explanation to legal compliance. Social proof explanation of legal compliance is, in addition to, and, therefore, should not be considered a replacement for, the existing frameworks for compliance. More often than not, the social proof in favor of or against compliance with different laws arises out of shared normative opinions about the content of the law or about the trust in the legal institutions enforcing the law. As such, even if our instinct is to imitate, we rectify the instinct if the imitation is against our normative or rational interests - such as our social, economic, or political interests. Therefore, over time, and through natural selection, most often the sticky social proof is the appropriate one within the context of the society. Focusing on correcting social proof without considering the underlying reasons for its persistence can in fact further deplete, rather than strengthen, legal legitimacy. The structural explanations-both about the legal and social institutions-to compliance and perception of law among different communities is also a relevant consideration that the present theory does not incorporate within its analysis. However, social proof can help explain situations where, even after addressing the underlying conflict, the compliance to law may be low due to the self-reinforcing tendencies of social proof. Alternatively, it also explains why certain laws, such as tax compliance, continue to impact behavior despite lower traditional compliance and greater benefits of non-compliance.

The important policy assertion of this Article is that there may not always be such a straight line between law, legal enforcement, and compliant behavior. There is an important layer of sociocognitive framework through which our brain processes all social and legal information that a legislation and its subsequent implementation provides us. Given the previous discussion on the systemic mismatch between the perception of individuals about law and the actual regulation, this socio-cognitive explanation becomes even more relevant. We should not presume an intent of compliance to law when we witness widespread compliant behavior in a society. Similarly, in corollary, non-compliance to a law may not always and only be indicative of a flaw in the content of law or its application. 
On the policy front, this explanation advocates for further research on how to encourage stronger voluntary compliance to laws. It emphasizes the need for greater focus on equipping citizens with legal information and inculcating a culture in favor of compliance. Utilizing the reinforcing powers of social proof can be an effective policy strategy for the dissemination of legal information and fostering greater compliance. It can enable the regulatory implementation discussion to go beyond increasing prosecution rates, stricter punishments, and improving implementation of every individual law at heavy costs to the state. This becomes especially relevant to developing economies which, often, face more compliance problems and are also more resource strapped. After all, making people believe there is a high cost of non-compliance need not require an actual increase in the cost of non-compliance.

Cite this article: Roy S (2021). Theory of Social Proof and Legal Compliance: A Socio-Cognitive Explanation for Regulatory (Non) Compliance. German Law Journal 22, 238-255. https://doi.org/10.1017/glj.2021.5 